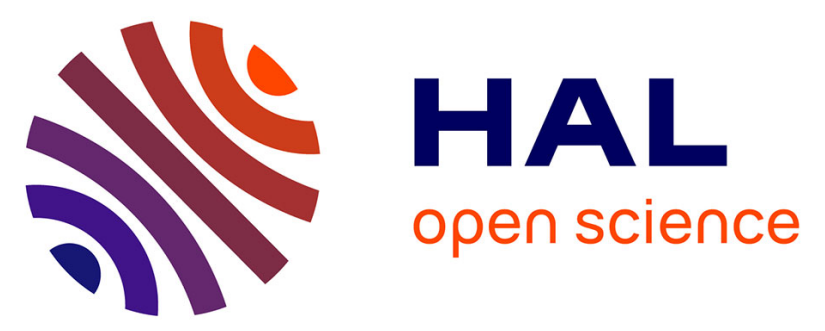

\title{
Evaluation of a new method for the collection and measurement of 8-isoprostane in exhaled breath for future application in nanoparticle exposure biomonitoring
}

Caroline Marie-Desvergne, Muriel Dubosson, Véronique Chamel Mossuz

\section{To cite this version:}

Caroline Marie-Desvergne, Muriel Dubosson, Véronique Chamel Mossuz. Evaluation of a new method for the collection and measurement of 8-isoprostane in exhaled breath for future application in nanoparticle exposure biomonitoring. Journal of Breath Research, 2018, 12 (3), pp.031001. 10.1088/1752$7163 /$ aabdf2 . cea-02150765

\section{HAL Id: cea-02150765 \\ https://hal-cea.archives-ouvertes.fr/cea-02150765}

Submitted on 11 Jun 2019

HAL is a multi-disciplinary open access archive for the deposit and dissemination of scientific research documents, whether they are published or not. The documents may come from teaching and research institutions in France or abroad, or from public or private research centers.
L'archive ouverte pluridisciplinaire HAL, est destinée au dépôt et à la diffusion de documents scientifiques de niveau recherche, publiés ou non, émanant des établissements d'enseignement et de recherche français ou étrangers, des laboratoires publics ou privés. 
ACCEPTED MANUSCRIPT

\section{Evaluation of a new method for the collection and measurement of 8- isoprostane in exhaled breath for future application in nanoparticle exposure biomonitoring}

To cite this article before publication: Caroline Marie-Desvergne et al $2018 \mathrm{~J}$. Breath Res. in press https://doi.org/10.1088/1752-7163/aabdf2

\section{Manuscript version: Accepted Manuscript}

Accepted Manuscript is "the version of the article accepted for publication including all changes made as a result of the peer review process, and which may also include the addition to the article by IOP Publishing of a header, an article ID, a cover sheet and/or an 'Accepted

Manuscript' watermark, but excluding any other editing, typesetting or other changes made by IOP Publishing and/or its licensors"

This Accepted Manuscript is (C) 2018 IOP Publishing Ltd.

During the embargo period (the 12 month period from the publication of the Version of Record of this article), the Accepted Manuscript is fully protected by copyright and cannot be reused or reposted elsewhere.

As the Version of Record of this article is going to be / has been published on a subscription basis, this Accepted Manuscript is available for reuse under a CC BY-NC-ND 3.0 licence after the 12 month embargo period.

After the embargo period, everyone is permitted to use copy and redistribute this article for non-commercial purposes only, provided that they adhere to all the terms of the licence https://creativecommons.org/licences/by-nc-nd/3.0

Although reasonable endeavours have been taken to obtain all necessary permissions from third parties to include their copyrighted content within this article, their full citation and copyright line may not be present in this Accepted Manuscript version. Before using any content from this article, please refer to the Version of Record on IOPscience once published for full citation and copyright details, as permissions will likely be required. All third party content is fully copyright protected, unless specifically stated otherwise in the figure caption in the Version of Record.

View the article online for updates and enhancements. 
Evaluation of a new method for the collection and measurement of 8-isoprostane in exhaled breath for future application in nanoparticle exposure biomonitoring

Caroline Marie-Desvergne, Muriel Dubosson, Véronique Chamel Mossuz

\section{NOTE}

\section{Address}

Univ. Grenoble Alpes, F-38000 France. CEA, NanoSafety Platform (SPNS), Medical Biology Laboratory (LBM), 17 rue des martyrs, F-38054 Grenoble, France.

Corresponding author: caroline.desvergne@cea.fr 


\section{List of abbreviations}

EBC: exhaled breath condensate

EIA(s): enzyme immunoassay(s)

$\mathrm{NP}(\mathrm{s})$ : nanoparticle(s)

RT: RTube

SB: SensAbues 


\section{1}

\section{Abstract \\ Background}

In the field of nanoparticle exposure biomonitoring, oxidative stress biomarkers measured in exhaled breath condensate appear promising to detect early respiratory effects in workers handling nanomaterials. However, condensation is known for its poor efficiency in collecting non-volatiles in exhaled breath, leading to the low sensitivity of such measurements. Moreover, to be easily used in field studies on large groups of workers, the collection device must be disposable and convenient.

\section{Objectives}

In this study, we have tested a totally disposable commercial device that allows for the easy dry collection of exhaled air after filtration on a patented filter. The suitability and efficiency of the Sens Abues (SB) device for collecting 8-isoprostane were evaluated and compared to the RTube (RT).

\section{Methods}

Seven healthy volunteers performed two 15-minute collections of exhaled breath, one with the SB and one with the RT. Blank devices were used to determine the background levels induced by each device. 8-isoprostane was measured in all samples using an EIA technique.

\section{Results}

The levels of 8-isoprostane in the exhaled breath of volunteers after collection with the SB were significantly higher than those after collection with the RT. Moreover, the levels obtained in volunteers with the SB were significantly higher than background levels obtained in blank devices, which was not the case for the RT.

\section{Conclusions}


This is the first study to report the ability of the SB device to collect and measure 8-isoprostane in exhaled breath. The proposed method offers better sensitivity than a classical collection with the RT device and should be further explored before future application in biomonitoring studies. 


\section{Introduction}

Engineered nanoparticles (NPs) are increasingly widespread in everyday consumer products. The number of researchers and workers involved in nanotechnology should reach about 6 millions by 2020 [1]. Due to the suspected toxicity of NPs, potentially leading to early stage fibrosis and carcinogenesis following inhalation [2], it is now accepted that biomonitoring activities may play a key role in preventing respiratory adverse effects in NP workers [3]. Although no biological indicator predictive of toxicity in humans has yet been validated, the stepwise approach suggested for defining novel biomarkers for NPs has led to the identification of a panel of candidate biomarkers of exposure and early effects [4]. Available epidemiological studies highlight the quantitative variations of several of these biomarkers following exposure, which might indicate an association between early adverse health effects and NP exposure [5]. Among these effects, oxidative stress is well represented, along with the common propensity of NPs to generate toxicity through oxidative pathways [6]. To evaluate oxidative stress, the measurement of isoprostanes is of principal interest since these are stable molecules found in various tissues and biological fluids, and specific of lipid peroxidation [7-9]. More precisely, isoprostanes form a complex family of naturally occurring lipids originating from a radical metabolism of the essential fatty acid, arachidonic acid. 8-iso-prostaglandin $\mathrm{F}_{2 \alpha}$ (8-isoprostane), is the most studied, and is regarded as the gold standard for detection of excessive chemical lipid peroxidation in humans [10]. As a sign of the interconnection between oxidative stress and inflammation, 8-isoprostane has also been described as an inflammatory mediator in human macrophages [11]. To counterbalance the non-specificity of oxidative stress and inflammation biomarkers, their measurement in exhaled breath condensate (EBC) appears particularly promising to assess potential respiratory effects following the inhalation of NPs. Historically, EBC has been explored as a research tool in various respiratory disorders. It is a non-invasive 
respiratory sampling that can also be used in the field of occupational health. It contains several molecules and non-volatile compounds issuing from the respiratory tract and potentially reflecting pulmonary pathobiology [12]. Very recent studies have shown an increase in 8isoprostane in the EBC of workers handling NPs compared to controls [13-15]. Among others, 8-isoprostane is proposed as a robust marker associated with nano-exposure, as it is not associated with other covariates [15].

One major challenge with measurements of biological molecules in EBC is to reach sufficient sensitivity since the matrix is highly diluted and biomarkers are found at very low levels. The most commonly used device in published data related to 8-isoprostane is the Ecoscreen (Jaeger, Germany), which offers electronic stable cold condensation. However, this device is not easily implementable in field studies, mainly due to its low portability. Turbo DECCS (Medivac, Italy) might be better suited to field studies due to its greater portability and entirely disposable collecting system, but only one sample can be collected at a time (unless different apparatus is available, which has a significant cost). That is why the RTube (RT) from Respiratory Research seems more appropriate for field studies since it is entirely portable and disposable while offering the possibility of different samplings at the same time. This is often a significant practical issue in occupational studies on a large group of workers [16]. Each RT works with an aluminum sleeve which is cooled in a freezer before sampling. Associations between 8isoprostane collected with the RT and pollution or respiratory disorders are mixed. While some studies fail to reveal respiratory impairment in the case of asthma [17-19] or exposure to polluted air $[20,21]$ when compared to healthy or non-exposed controls, some other studies demonstrate significant influence of various air pollution parameters on exhaled 8-isoprostane, especially in youth [22-25]. These variegated results might be related to low detection levels, since it is now admitted that condensation is not a very efficient method for collecting nonvolatiles in exhaled breath [26]. The sampling of exhaled breath without any condensation step 
might be a promising solution for the measurement of non-volatile compounds such as 8isoprostane.

In the past few years, the SensAbues (SB) breathalyser with an electrostatic air filter developed by the Karolinska Institutet has been investigated for its suitability in the field of drug abuse testing. Methods were validated for various drugs collected with this disposable commercial device in exhaled breath with quantification limits ranging from 2 to 6 pg/filter using mass spectrometry $[27,28]$. The collection is reported to be convenient, rapid, safe and well accepted by volunteers. Two feasibility studies have also demonstrated that phosphatidylethanols for testing alcohol consumption, along with phosphatidylcholines for surfactant analysis, could be analyzed in exhaled breath collected with the SB [29, 30]. From a chemical point of view, 8isoprostane might be related to these hydrophobic lipid compounds. That is why we have aimed in this paper to evaluate the suitability and efficiency of the SB for collecting 8-isoprostane, in comparison with exhaled breath condensate collection using the RT. 


\section{Methods}

\subsection{Subjects and collection of EBC and exhaled air}

Seven volunteers were recruited among the laboratory staff and each gave written informed consent. Each volunteer performed two collections of exhaled air, one with the RT and one with the SB, on two separate days less than three days apart, at the same time of the day.

Prior to the collection, RT devices were washed seven times with ultrapure water as explained elsewhere [16]. Moreover, a filter (Virobac II, France Neir) was added to the inlet valve of each RT in order to prevent unwanted substances from entering the respiratory tract during the sampling. The sampling with the RT was performed for 15 minutes, with a nose-clip, at an initial condensation temperature of $-20^{\circ} \mathrm{C}$. The $\mathrm{EBC}$ was immediately frozen at $-80^{\circ} \mathrm{C}$ after collection in the RT collection tube. The EBC samples were characterized by their total volume and total protein concentration (MicroBCA Assay, Protein quantitation kit, Uptima Interchim). The collection with the SB device was carried out in line with the manufacturer's recommendations, with inhalation through the nose and exhalation through the mouth. Each subject breathed tidally for 15 minutes inside the device for comparison with the RT. After the collections, the devices were capped and immediately frozen at $-80^{\circ} \mathrm{C}$.

In order to evaluate the analytical background induced by each device, blank RT and SB were prepared. The blank RT consisted in $1.5 \mathrm{~mL}$ of ultrapure water incubated in new devices for 15 min. The blank SB consisted in unused new devices. Both blanks were prepared in the same manner as real samples.

\subsection{EIA}

Samples collected with the RT were analyzed half diluted in the EIA buffer, as recommended for low salt concentrated samples to better mimic the standard matrix. Samples collected with the SB were prepared as prescribed by the manufacturer. Briefly, the filters were extracted three 


\subsection{Statistics}

Mann-Whitney non-parametric tests were used to compare the levels of 8-isoprostane between the different groups. Additionally, the Wilcoxon signed-rank test was used to compare the levels of 8-isoprostane collected either with the RT or the SB for each volunteer. The $p$ value $p<0.05$ was considered statistically significant.

\section{Results}

\subsection{Description of the volunteers and EBC characteristics}

Volunteers were mainly women (six women and one man), non-smokers (5 non-smokers and 2 smokers) and aged $37 \pm 12$ years. All of them were healthy with no respiratory inflammation or fever reported at the time of the collections. 
The EBC mean volume and mean total protein concentration obtained with the RTube over $15 \min$ were $1254 \pm 157 \mu \mathrm{L}$ and $1.4 \pm 0.5 \mu \mathrm{g} / \mathrm{mL}$ respectively, which is consistent with previous data obtained on more than 400 subjects [16].

\subsection{Comparison of 8-isoprostane levels obtained with each device in volunteers} compared to blank devices

All the levels of 8-isoprostane measured in blanks or on volunteers, with both devices, were above the assay detection limit. However, five out of seven volunteers gave 8-isoprostane levels below the assay quantification limit with the RT, while all volunteers had 8-isoprostane levels above the assay quantification limit with the SB.

In order to compare the results obtained with the RT and the SB devices, they were expressed as total 8-isoprostane collected during the sampling period $(15 \mathrm{~min})$ in $\mathrm{pg}$. For the $\mathrm{SB}$ this amount corresponded to the total quantity of 8-isoprostane eluted from the filter after collection, and for the RT it was calculated from the EBC concentration and the total volume of EBC collected for 15 minutes. The results are presented in Figure 1.

With the RT, the levels found in volunteers were not significantly different from those found in RT blanks $(4.1 \pm 0.6$ vs $6.1 \pm 1.9 \mathrm{pg})$. This background level was also similar to that obtained in SB blanks $(5.2 \pm 1.6 \mathrm{pg})$. However, the levels found in volunteers after collection with the SB $(16.0 \pm 3.2 \mathrm{pg})$ were significantly higher than the levels in the SB blanks (MannWhitney, $\mathrm{p}<0.05$ ) and in volunteers collected with the RT (Mann-Whitney, $\mathrm{p}<0.01$ ).

When the levels of 8-isoprostane collected with both devices for each volunteer were studied in pairs, those after collection with the SB were still significantly higher than those with the RT (Wilcoxon signed-rank test, $\mathrm{p}<0.05$ ) (Figure 2). The mean ratio between the SB level 
and the RT level for each volunteer was $3.9 \pm 0.7$, which corresponds to a variation coefficient inferior to $20 \%$.

\section{Discussion}

In this feasibility study we have tested the suitability of the SB disposable commercial device for the collection and measurement of 8-isoprostane in exhaled breath, in comparison with the RTube. The collections were performed on healthy volunteers in order to identify the sensitivity of the method and its ability to detect background levels. When seeking to identify early effects on workers, the method should be as sensitive as possible. Moreover, blank devices were used to determine the total analytical background of the method and compare it to the levels obtained in the study volunteers.

With the RT, most levels found in volunteers fell between the EIA detection limit and its quantification limit, which is usually interpreted as very low levels of 8-isoprostane. However, these levels are not significantly higher than the levels detected in blank devices, indicating that this background level might be of non-specific origin. While EIAs are of widespread use, their specificity and selectivity can be challenging [31]. This casts light on the importance of ascertaining the detection limit of the method taking the collection devices into account, a rare consideration in practice.

Apart from the comparison with the blanks, our results on the low levels found with the RT device agree with available published data. Higher levels in EBC are generally obtained with the Ecoscreen device. It has been reported that the levels of different biomarkers measured in EBC, including 8-isoprostane, tend to be lower after collection with the RT than after collection with the Ecoscreen [32]. According to the authors, this difference in the collection efficiency may be due to the collection temperature, which is stable with the Ecoscreen but not with the 
RT. Indeed, the temperature of the sampling system is one of the key parameters governing condensation efficacy and sampling reproducibility [26].

Dry collection appears appealing as a way to overcome the condensation issue, especially since collection efficiency might be improved for non-volatile compounds. In the study by Larsson et al. [33], surfactant protein A and albumin were detected in $100 \%$ of dry samples collected with the PExA method, against $21 \%$ and $0 \%$ respectively of liquid samples collected with the Ecoscreen. The disposable SB device, which is also based on dry collection, thus appears interesting for its collection efficiency for 8-isoprostane measurement. In our study, the levels obtained in volunteers were almost four times higher than those obtained/with the RT, and these levels were significantly higher than the background level obtained in blank devices. Since the SB is performed without the use of a nose-clip and the RT is used with a nose-clip, the question is raised of whether the better efficiency of the SB could be due to the different mode of inhalation. However, although oral versus nasal inhalation is suspected to have an influence on the composition of EBC, it has been reported that the levels of thromboxane B2, which is produced by the metabolism of arachidonic acid such as 8-isoprostane and has a very close chemical structure, are not significantly different in EBC collected with or without a nose clip. Moreover, no significant difference is found between the levels of thromboxane B2 in nasal lavages and EBC samples [34]. This might indicate that the higher levels of 8-isoprostane obtained with the SB in our study might well be attributable to the collection mode rather than the inhalation mode. To confirm the specificity of 8-isoprostane collection with the SB, tandem mass spectrometry analyses coupled with high performance liquid chromatography should be envisioned in the future.

From a practical point of view, collection with the SB is better accepted by volunteers than collection with the RT, since nasal inhalation is less restrictive than oral inhalation. 
To enlarge the scope of this study, the adequacy of the SB device for collecting other biomarkers should now be studied in order to determine what kind of panel might be used for the detection of early respiratory effects. Interestingly, the fact that the SB is suitable to collect phosphatidylethanols and phosphatidylcholines opens the way to the possibility of collecting and measuring peroxidised phospholipids for lipidomics approaches. Indeed, pulmonary peroxidised phospholipids are produced in specific relative proportions following carbon nanotubes inhalation in mice, which could be a means of overcoming the non-specificity of oxidative biomarkers in the case of NP exposure [35].

However, from a technical point of view, only hydrophobic compounds are susceptible to being efficiently collected by the patented filter included in the SB. Therefore, the application of the SB would not be contradictory to classical EBC collection, which/is more suitable for soluble compounds such as metals.

Finally, the potential standardization of the collection using the SB needs to be further assessed. Because the measurement of soluble components that can be proposed for EBC standardization are not prone to be trapped by the SB filter, we have based our comparison on the amount of 8isoprostane exhaled during a fixed duration of collection for both types of sampling. Although no consensual reference method for EBC standardization is now available, this approach is one of the possibilities to reduce the confounding influence of dilution of EBC samples [26]. Additionally, the possibility of measuring total exhaled air during the collections should be explored since this is now considered as a key criterion for the standardization of exhaled breath samplings. In the future, the already described measurement of the main surfactant lipid component, dipalmitoylphosphatidylcholine [30], could also be evaluated as a way to standardize the levels of biomarkers measured with the SB. 


\section{Conclusion}

This is the first study to report the collection and measurement of 8-isoprostane in exhaled breath using the SB device. The collection efficiency is better than with the RT and more data are now required to further explore the possibilities offered by this device.

\section{Acknowledgements}

None of the authors have any competing interests in the manuscript. None of the authors or their institutes have any financial or non-financial benefit from the product developers or manufacturers. CM-D, MD, and VCM and take responsibjlity for the contents of the manuscript, the integrity of the data, and the accuracy of the data analysis, including and especially any adverse effects. CM-D was responsible for the design of the study and the writing of the manuscript. MD was responsible for the EIA measurements. MD and VCM contributed to the revision of the manuscript.

This project has been funded by collaborative funding from the French region of AuvergneRhône-Alpes, the ARS Auvergne-Rhône-Alpes (regional health agency), and the DREAL Auvergne-Rhône-Alpes (regional authority for environment, development and housing) after selection by EnvitéRA (Health-Environment platform in Rhône-Alpes). 


\section{References}

1. Roco M. The long view of nanotechnology development: the National Nanotechnology Initiative at 10 years. J Nanopart Res. 2011;13:427-45.

2. Xia T, Zhu Y, Mu L, Zhang ZF, Liu S. Pulmonary diseases induced by ambient ultrafine and engineered nanoparticles in twenty-first century. National science review. 2016;3(4):41629.

3. Iavicoli I, Leso V, Manno M, Schulte PA. Biomarkers of nanomaterial exposure and effect: current status. J Nanopart Res. 2014;16:2302.

4. Bergamaschi E. Human Biomonitoring of Engineered Nanoparticles: An Appraisal of Critical Issues and Potential Biomarkers. Journal of Nanomaterials. 2012;2012(564121).

5. Liou SH, Tsai CS, Pelclova D, Schubauer-Berigan MK, Schulte PA. Assessing the first wave of epidemiological studies of nanomaterial workers. J Nanopart Res. 2015;17:413.

6. Moller P, Jacobsen NR, Folkmann JK, Danielsen PH, Mikkelsen L, Hemmingsen JG, Vesterdal LK, Forchhammer L, Wallin H, Loft S. Role of oxidative damage in toxicity of particulates. Free Radic Res. 2010;44(1):1-46.

7. Cracowski JL. [Isoprostanes: a putative key role in vascular diseases]. Rev Med Interne. 2004;25(6):459-63.

8. Montuschi P. Exhaled breath condensate: 8-isoprostane and eicosanoids. Eur Respir Mon. 2010;49:196-206.

9. Roberts LJ, Morrow JD. Measurement of F(2)-isoprostanes as an index of oxidative stress in vivo. Free Radic Biol Med. 2000;28(4):505-13.

10. van 't Erve TJ, Lih FB, Kadiiska MB, Deterding LJ, Eling TE, Mason RP. Reinterpreting the best biomarker of oxidative stress: The 8-iso-PGF(2alpha)/PGF(2alpha) ratio distinguishes chemical from enzymatic lipid peroxidation. Free Radic Biol Med. 2015;83:245-51. 
11. Scholz H, Yndestad A, Damas JK, Waehre T, Tonstad S, Aukrust P, Halvorsen B. 8isoprostane increases expression of interleukin-8 in human macrophages through activation of mitogen-activated protein kinases. Cardiovascular research. 2003;59(4):945-54.

12. Mutlu GM, Garey KW, Robbins RA, Danziger LH, Rubinstein I. Collection and analysis of exhaled breath condensate in humans. Am J Respir Crit Care Med. 2001;164(5):7317.

13. Liou SH, Wu WT, Liao HY, Chen CY, Tsai CY, Jung WT, Lee HL. Global DNA methylation and oxidative stress biomarkers in workers exposed to metal oxide nanoparticles. Journal of hazardous materials. 2017;331:329-35.

14. Pelclova D et al. Oxidative stress markers are elevated in exhaled breath condensate of workers exposed to nanoparticles during iron oxide pigment production. J Breath Res. 2016;10(1):016004.

15. Pelclova D et al. Markers of lipid oxidative damage among office workers exposed intermittently to air pollutants including nanoTiO2 particles. Reviews on environmental health. 2017;32(1-2):193-200.

16. Marie-Desvergne $\mathrm{C}$ et al. Assessment of nanoparticles and metal exposure of airport workers using exhaled breath condensate. J Breath Res. 2016;10(3):036006.

17. Fritscher LG, Post M, Rodrigues MT, Silverman F, Balter M, Chapman KR, Zamel N. Profile of eicosanoids in breath condensate in asthma and COPD. J Breath Res. 2012;6(2):026001.

18. Komakula S, Khatri S, Mermis J, Savill S, Haque S, Rojas M, Brown L, Teague GW, Holguin F. Body mass index is associated with reduced exhaled nitric oxide and higher exhaled 8-isoprostanes in asthmatics. Respir Res. 2007;8:32.

19. Sood A, Qualls C, Seagrave J, McDonald J, Shohreh R, Chiavaroli A, Schuyler M. Effect of allergen inhalation on airway oxidant stress, using exhaled breath condensate 8- 
isoprostane, in mild asthma. The Journal of asthma : official journal of the Association for the Care of Asthma. 2013;50(5):449-56.

20. Murgia N, Barregard L, Sallsten G, Almstrand AC, Montuschi P, Ciabattoni G, Olin AC. 8-isoprostane in exhaled breath condensate after experimental exposure to wood smoke in humans. Journal of biological regulators and homeostatic agents. 2016;30(1):263-70.

21. Pirozzi C, Sturrock A, Weng HY, Greene T, Scholand MB, Kanner R, Paine R, 3rd. Effect of naturally occurring ozone air pollution episodes on pulmonary oxidative stress and inflammation. International journal of environmental research and public health. 2015;12(5):5061-75.

22. Guidance Notes on Dermal Absorption N 156. Paris: 2011.

23. De Prins $\mathrm{S}$ et al. Airway oxidative stress and inflammation markers in exhaled breath from children are linked with exposure to black carbon. Environment international. 2014;73:440-6.

24. Patel MM, Chillrud SN, Deepti KC, Ross JM, Kinney PL. Traffic-related air pollutants and exhaled markers of airway inflammation and oxidative stress in New York City adolescents. Environmental research. 2013;121:71-8.

25. Rosa MJ, Yan B, Chillrud SN, Acosta LM, Divjan A, Jacobson JS, Miller RL, Goldstein IF, Perzanowski MS. Domestic airborne black carbon levels and 8-isoprostane in exhaled breath condensate among children in New York City. Environmental research. 2014;135:10510.

26. Horvath I et al. A European Respiratory Society technical standard: exhaled biomarkers in lung disease. Eur Respir J. 2017;49(4).

27. Beck O, Stephanson N, Sandqvist S, Franck J. Detection of drugs of abuse in exhaled breath using a device for rapid collection: comparison with plasma, urine and self-reporting in 47 drug users. J Breath Res. 2013;7(2):026006. 
28. Stephanson N, Sandqvist S, Lambert MS, Beck O. Method validation and application of a liquid chromatography-tandem mass spectrometry method for drugs of abuse testing in exhaled breath. J Chromatogr B Analyt Technol Biomed Life Sci. 2015;985:189-96.

29. Helander A, Ullah S, Beck O. Phosphatidylethanols in breath: a possible noninvasive screening test for heavy alcohol consumption. Clin Chem. 2015;61(7):991-3.

30. Ullah S, Sandqvist S, Beck O. Measurement of Lung Phosphatidylcholines in Exhaled Breath Particles by a Convenient Collection Procedure. Anal Chem. 2015;87(22):11553-60.

31. Smith KA, Shepherd J, Wakil A, Kilpatrick ES. A comparison of methods for the measurement of 8-isoPGF(2alpha): a marker of oxidative stress. Annals of clinical biochemistry. 2011;48(Pt 2):147-54.

32. Leung TF, Li CY, Yung E, Liu EK, Lam CW, Wong GW. Clinical and technical factors affecting $\mathrm{pH}$ and other biomarkers in exhaled breath condensate. Pediatric pulmonology. 2006;41(1):87-94.

33. Larsson P, Mirgorodskaya E, Samuelsson L, Bake B, Almstrand AC, Bredberg A, Olin AC. Surfactant protein A and albumin in particles in exhaled air. Respir Med. 2012;106(2):197204.

34. Vass G, Huszar E, Barat E, Valyon M, Kiss D, Penzes I, Augusztinovicz M, Horvath I. Comparison of nasal and oral inhalation during exhaled breath condensate collection. Am J Respir Crit Care Med. 2003;167(6):850-5.

35. Shvedova AA, Pietroiusti A, Fadeel B, Kagan VE. Mechanisms of carbon nanotubeinduced toxicity: focus on oxidative stress. Toxicol Appl Pharmacol. 2012;261(2):121-33. 


\section{Figures}

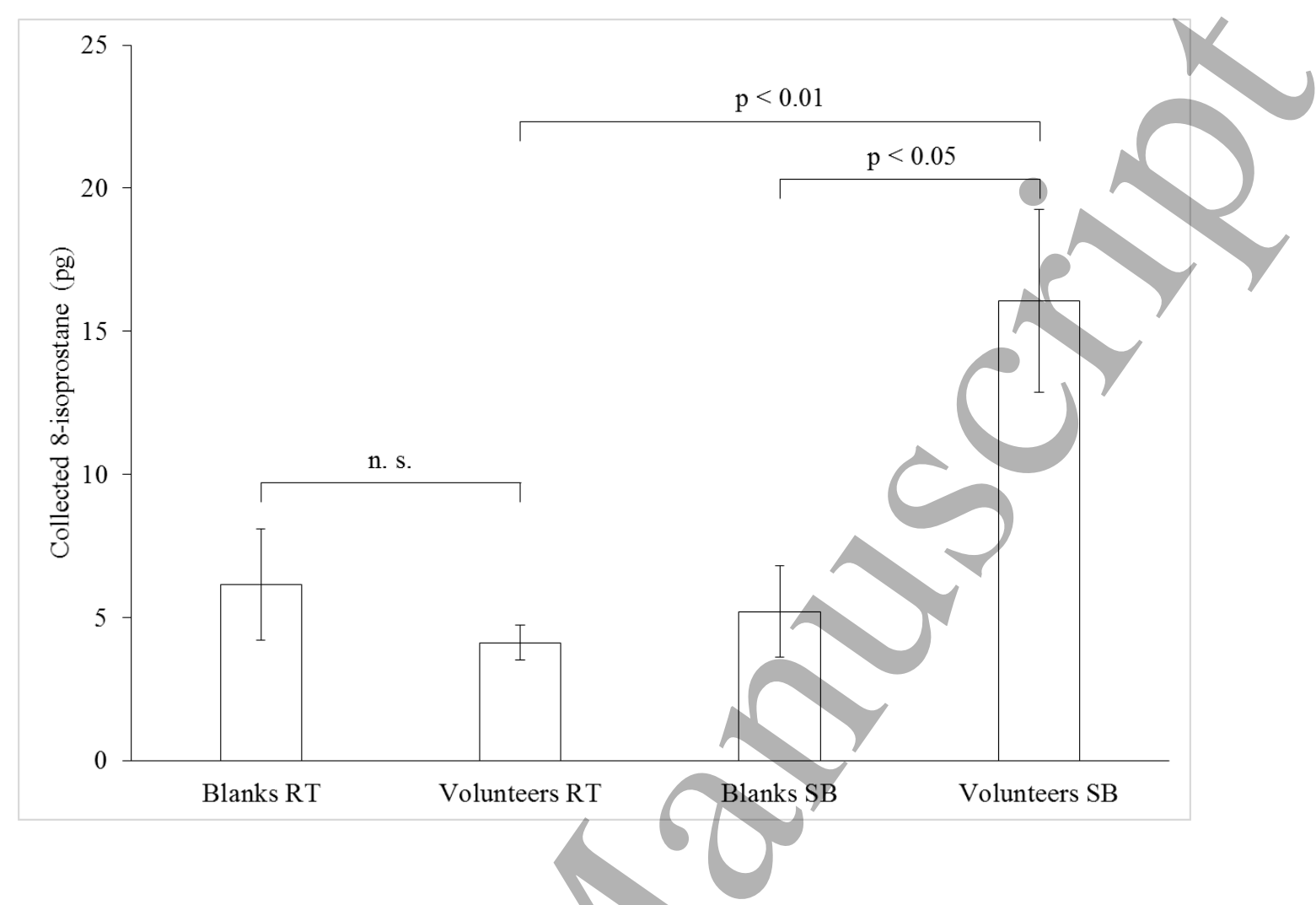

Figure 1: Comparison of the quantity of 8 -isoprostane collected in volunteers $(n=7)$ for 15 minutes either with the RTube (RT) or with the SensAbues (SB), with background levels found in blank devices $(n=3)$. n.s.: non-significant. 


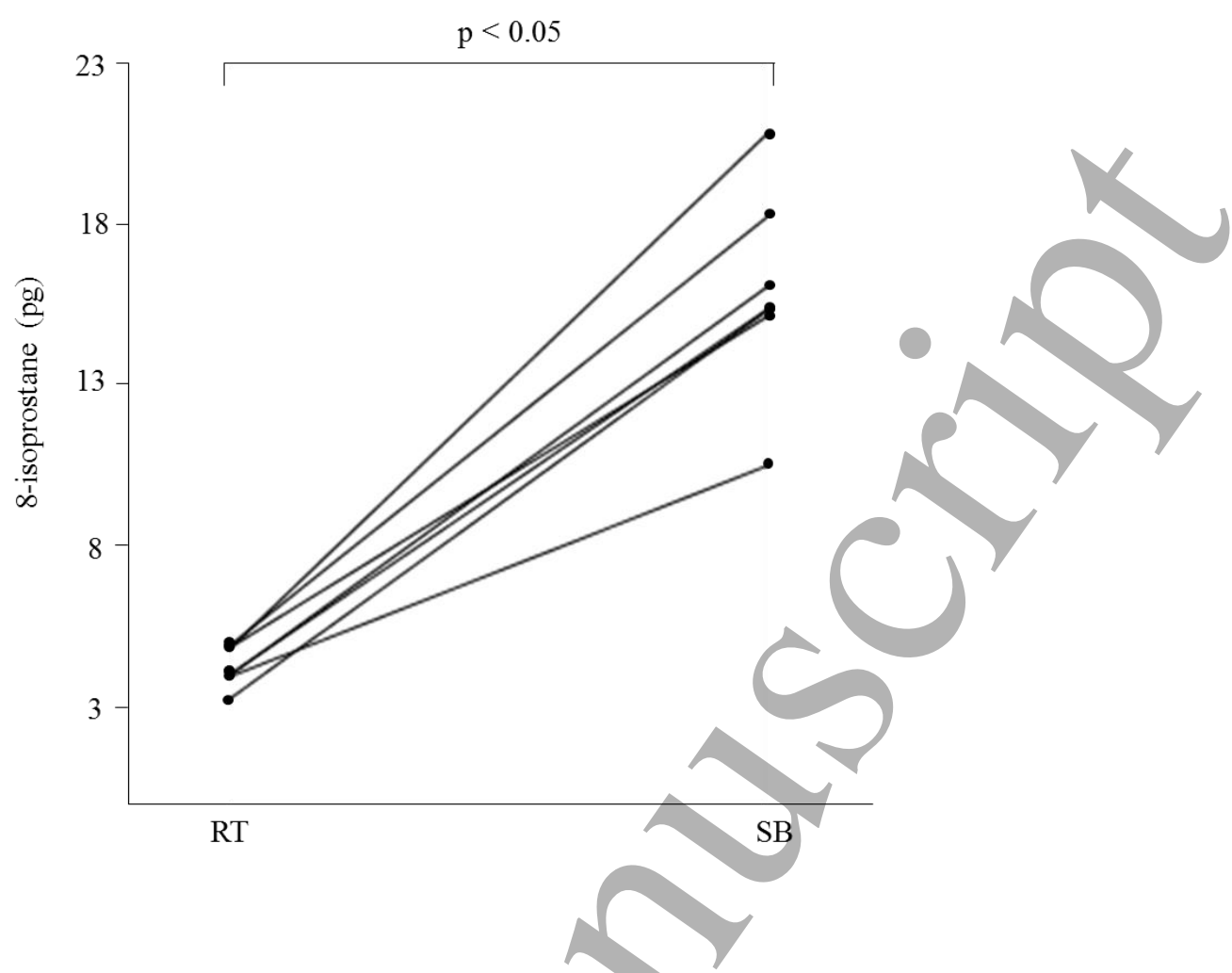

Figure 2: Amount of 8-isoprostane (pg) collected in 7 volunteers after a 15-minute collection with the RTube (RT) device and with the SensAbues (SB) device. 